\title{
Sanitização de cenoura minimamente processada com nanopartículas de prata
}

\author{
Sanitization of minimally processed carrot with silver nanoparticles
}

\author{
Emiliane Andrade Araújo ${ }^{\text {I }}$ Lorena Ribeiro ${ }^{\text {II }}$ Patrícia Campos Bernardes ${ }^{\text {III }}$ \\ Milene Therezinha das Dores ${ }^{I I}$ José Felício Queiroz Fialho Júnior ${ }^{\mathrm{IV}}$
}

\section{RESUMO}

A produção de cenoura em grande escala na região de Rio Paranaíba coloca essa região em posição de destaque no cenário nacional. No entanto, é relatado que ocorre significativa quantidade de sobras após a colheita. $O$ aproveitamento do material descartado na cadeia de alimentos pode se concretizar pelo processamento mínimo, como uma alternativa de agregação de valor. A etapa de sanitização é de extrema importância durante a produção de vegetais minimamente processados. Nesse contexto, objetivou-se estudar o efeito antimicrobiano de nanopartículas de prata na sanitização de cenoura minimamente processada, obtida a partir do aproveitamento das sobras de cenouras da colheita da cidade de Rio Paranaiba, bem como o estudo da termodinâmica de adesão de diferentes estirpes bacterianas na superficie da cenoura sanitizada. Observouse que as nanoparticulas de prata (6mg $\left.\mathrm{L}^{-1}\right)$ apresentaram bons resultados, quando comparadas aos sanitizantes hipoclorito de sódio $\left(100 \mathrm{mg} \mathrm{L}^{-1}\right)$ e dicloroisocianurato de sódio (150mg $L^{-1}$ ), na descontaminação da cenoura minimamente processada sobre microrganismos mesófilos aeróbios; Pseudomonas spp.; bactérias láticas; e coliformes a $35^{\circ} \mathrm{C}$. Verificou-se também que a superficie da cenoura apresenta características hidrofilicas que podem dificultar a adesão bacteriana. Esse fato foi confirmado na avaliação de termodinâmica de adesão, que foi desfavorável para Staphylococcus aureus, Escherichia coli e Listeria innocua, sendo mais desfavorável para as interações envolvendo as superficies de cenoura sanitizadas com nanoparticulas de prata.

Palavras-chave: hortaliça, nanopartículas de prata, energia livre de adesão bacteriana, hidrofobicidade.

\section{ABSTRACT}

The carrot production on a large scale in the region of Rio Paranaiba places the region in a prominent position on the national scene. However, it is reported that a significant amount of scraps occurs after harvest. The use of discarded material in the food chain can be realized by minimal processing, as an alternative of adding value. A sanitization step is very important during the production of minimally processed vegetables. In this context, this research aimed to study the antimicrobial effect of silver nanoparticles in the sanitization of minimal processing carrot from discarded carrot harvested at Rio Paranaiba city, as well as study the thermodynamics adhesion for different bacterial strains in sanitized carrot surface. It was observed that silver nanoparticles (6mg $\left.L^{-1}\right)$ showed good results when was compared to sodium hypochlorite $\left(100 \mathrm{mg} \mathrm{L}^{-1}\right)$ and sodium dichloroisocyanurate $\left(150 \mathrm{mg}^{-1}\right)$ in reducing populations of aerobic mesophilic microorganism; Pseudomonas spp. lactic acid bacteria and coliforms at $35^{\circ} \mathrm{C}$ present in carrot. It was also found that the surface of carrot has hydrophilic characteristics which can prevent bacterial adhesion. This fact was confirmed that thermodynamic evaluation of adhesion that was unfavorable for Staphylococcus aureus, Escherichia coli and Listeria innocua, and more thermodynamically unfavorable for interactions involving carrot surfaces sanitized with silver nanoparticles.

Key words: vegetable, silver nanoparticles, free energy of bacterial adhesion, hydrophobicity.

\section{INTRODUÇÃO}

A popularidade de frutas e hortaliças minimamente processadas tem aumentado em virtude dos benefícios proporcionados na saúde e também em razão da busca dos consumidores por alimentos mais saudáveis. $\mathrm{O}$ aumento na demanda pelos produtos minimamente processados representa

\footnotetext{
Instituto de Ciências Exatas e Tecnológicas, Universidade Federal do Triangulo Mineiro (UFTM), Av. Doutor Randolfo Borges Júnior, 1250, Bairro Universidade, 38064-200, Uberaba, MG, Brasil. E-mail: emilianeandrade@yahoo.com.br. Autor para correspondência. IIInstituto de Ciências Agrárias, Universidade Federal de Viçosa (UFV), Rio Paranaíba, MG, Brasil.

IIIDepartamento de Engenharia de Alimentos, Centro de Ciências Agrárias, Universidade Federal do Espirito Santo (UFES), Alegre, ES, Brasil.

${ }^{\text {IV }}$ Departamento de Tecnologia de Alimentos, UFV, Viçosa, MG, Brasil.
} 
um desafio para pesquisadores e processadores em tornar o produto mais estável e seguro do ponto de vista microbiológico (GARCIA et al., 2003).

A segurança do alimento minimamente processado é uma preocupação cada vez maior em empresas de alimentos. Surtos de contaminação podem significar o fim de uma empresa ou mesmo de toda uma cadeia produtiva. Diversas empresas têm investido pesadamente na obtenção de matériasprimas de excelente qualidade sanitária e se empenhado para garantira inocuidade do produto (MORETTI, 2008).

Aetapa de sanitização após o processamento é de suma importância, principalmente para vegetais que se desenvolvem diretamente no solo, como raízes e tubérculos. A sanitização é também importante para vegetais que, após cortados, apresentam alto extravasamento de líquido na superfície. É importante enfatizar que a qualidade do produto final é otimizada quando a sanitização é aliada com métodos de conservação, como refrigeração e embalagem em atmosfera modificada (BOAS et al., 2007).

A sanitização no processamento mínimo de frutas e hortaliças visa a destruir os microrganismos patogênicos e reduzir os deteriorantes. A baixa eficiência dos sanitizantes usados para descontaminação das superfícies pode ser atribuída à incapacidade dos componentes ativos da solução de tratamento em alcançar os sítios de colonização das células microbianas. A remoção dos microrganismos pode ser dificultada por infiltração das células em fissuras e espaços intercelulares, além da possibilidade de formação de biofilmes no tecido vegetal e nos equipamentos que entram em contato com o alimento (MORETTI, 2008).

Em razão da baixa eficácia dos sanitizantes usuais na redução de contaminantes em produtos minimamente processados, com possibilidade de adesão microbiana, e além do fato da sanitização a base de cloro poder resultar na formação de produtos tóxicos à saúde, como os trihalometanos, tem-se a necessidade de desenvolvimento de sanitizantes alternativos que possuam a capacidade de reduzir a carga microbiana, além serem menos corrosivos para equipamentos e menos tóxico para seres humanos (SIGUA et al., 2010).

A síntese de nanopartículas tem atraído à atenção dos pesquisadores, em virtude de diferentes características físicas e químicas, que possuem como alta relação superfície/volume, que não são encontradas em materiais convencionais e que permitem aplicações atrativas em vários campos como medicina, biotecnologia, catálise, óptica e indústria de alimentos (GÚZMAN et al., 2009).

O uso de nanopartículas de prata como agente antibacteriano tem sido muito pesquisado e sua atividade pode ser aplicada na medicina para reduzir infecções, bem como prevenir colonização bacteriana em superfícies de prótese, cateteres, materiais odontológicos e, na indústria de alimentos, em superfícies de aço inoxidável (DALLAS et al., 2011). Podem ser empregadas também no controle microbiano em têxteis e no tratamento de água (GUZMÁN et al., 2009). Na síntese das nanopartículas de prata, deve-se dar ênfase no controle do tamanho das partículas, pois o efeito bactericida é influenciado pelas dimensões da partícula, tendo as menores partículas os melhores efeitos (SHAHVERDI et al., 2007).

Nesse contexto, este trabalho objetivou comparar a ação antimicrobiana de nanopartículas de prata com os sanitizantes: hipoclorito de sódio e dicloisocianurato de sódio na produção de cenouras minimamente processadas. Em adição, estudouse também a termodinâmica de adesão das estirpes Staphylococcus aureus (ATCC 6538), Escherichia coli (ATCC 11229) e Listeria innocua (ATCC 33090) em superfícies de cenoura minimamente processadas e sanitizadas com diferentes agentes antimicrobianos.

\section{MATERIAL E MÉTODOS}

Produção de cenoura minimamente processada

A etapa de produção de cenoura minimamente processada ocorreu no Centro Vocacional Tecnológico (CVT) do Rio Paranaíba. As cenouras descartadas, matéria-prima para a produção, foram recolhidas do campo e levadas para o laboratório. Estas cenouras consideradas para descarte estavam fora do padrão comercial por terem sido caracterizadas como bifurcadas, rachadas, quebradas, injuriadas ou por possuírem tamanho inadequado.

O processamento mínimo da cenoura para o seu consumo in natura inclui várias operações, realizadas de modo a obter um produto fresco, saudável e seguro do ponto de vista microbiológico. As etapas envolvidas no processamento mínimo da cenoura foram: recepção e pesagem da matéria-prima, resfriamento, seleção e classificação, lavagem e preparo (descascamento e corte), enxague inicial, sanitização e enxague final, centrifugação e seleção, embalagem.

Após o preparo da matéria-prima, foi realizada imersão rápida em água a $5^{\circ} \mathrm{C}$ para remover o suco celular extravasado por rompimento das 
membranas celulares durante o corte. Na etapa de sanitização, os produtos minimamente processados foram imersos em água a $5^{\circ} \mathrm{C}$ (controle) e nos diferentes agentes sanitizantes (hipoclorito de sódio $100 \mathrm{mg} \mathrm{L}^{-1}$; dicloroisocianurato de sódio $150 \mathrm{mg} \mathrm{L}^{-1}$ e nanopartículas de prata $6 \mathrm{mg} \mathrm{L}^{-1}$ ) por um tempo de 10 minutos, seguido de enxágue em água $\left(5^{\circ} \mathrm{C}\right)$, por 5 minutos, para retirada do excesso de produto. Após a etapa de sanitização, ocorreu a centrifugação por meio de centrífuga doméstica, por dois minutos, para retirar o excesso de água presente no produto em razão da lavagem, sanitização e enxágue. $\mathrm{Na}$ etapa final, após a pesagem, os produtos foram acondicionados adequadamente e refrigerados para aguardar a realização das análises propostas.

Produção de nanopartículas de prata

As nanopartículas de prata foram preparadas a partir de uma solução aquosa, composta do surfactante brometo de dodeciltrimetilamônio (Dotab)(Sigma, São Paulo, Brasil), cuja concentração micelar crítica é $0,0156 \mathrm{M}$ e de sulfadiazina de prata (SAg) (Sigma, São Paulo, Brasil) na concentração de 0,028 M. A dispersão foi submetida a uma agitação suficiente para garantir a mistura completa e, em seguida, foi realizada centrifugação da dispersão a $15.000 \times \mathrm{g}$ durante 5 minutos em centrífuga (SIGMA Laboratory Centrifuges 3k30). Após centrifugação, o sobrenadante de coloração amarela obtida, contendo as nanopartículas, foi separado do pellet e utilizado para a sanitização da cenoura minimamente processada.

Análises microbiológicas da cenoura

As amostras de cenoura foram avaliadas microbiologicamente após o processamento final da cenoura. Os procedimentos empregados no preparo das amostras foram realizados de acordo com a metodologia da American Public Health Association (DOWNES e ITO, 2001), descrita no Compendium of Methodos for the Microbiological Examination of Foods.

A contagem de microrganismos mesófilos aeróbios das amostras de cenoura foi realizada pela técnica de plaqueamento por profundidade, utilizando o ágar padrão para contagem e incubação a $35^{\circ} \mathrm{C} / 48 \mathrm{~h}$. A determinação de coliformes a $35^{\circ} \mathrm{C}$ nas amostras foi realizada pela técnica de Petrifilm $^{3 \mathrm{M}}$ com incubação a $35^{\circ} \mathrm{C} / 48 \mathrm{~h}$. Já a enumeração de Pseudomonas spp. foi realizada por plaqueamento em profundidade com ágar Cetrimide e incubação a $27^{\circ} / 48 \mathrm{~h}$. As bactérias láticas das amostras foram enumeradas por plaqueamento por profundidade com sobrecamada, utilizando o ágar Lactobacillus-MRS com incubação a $35^{\circ} \mathrm{C} / 48 \mathrm{~h}$.
Medida do ângulo de contato para superfícies da cenoura minimamente processada

Os ângulos de contato entre a superfície do vegetal e água, formamida e $\alpha$-bromonaftaleno foram determinados usando o goniômetro (Kruss, Germany). A medida foi realizada a partir do ângulo de contato de uma gota de $2,0 \mu \mathrm{L}$ a cada segundo durante 30 segundos consecutivos para todos os líquidos e superfícies avaliadas. As medidas foram obtidas à temperatura de $25^{\circ} \mathrm{C}$. Três repetições foram feitas para cada líquido em cada superfície. Esta mesma metodologia foi novamente empregada para a superfície da cenoura após a sanitização. Os valores de ângulo de contato obtidos são necessários para a determinação da energia livre de interação hidrofóbica e de adesão.

Medida do ângulo de contato para microrganismo Para a medição do ângulo de contato da superfície das células bacterianas, as medidas foram realizadas sobre uma camada de células vegetativas das seguintes bactérias Staphylococcus aureus (ATCC 6538), Escherichia coli (ATCC 11229) e Listeria innocua (ATCC 33090), usando o método descrito por BUSSCHER et al. (1984). Resumidamente, uma suspensão bacteriana é filtrada sobre uma membrana de acetato de celulose, formando uma camada de células para que o ângulo de contato possa ser medido.

Determinação de energia livre de interação hidrofóbica e de adesão

A energia livre de interação hidrofóbica $\Delta \mathrm{G}_{\mathrm{sas}}{ }^{\text {TOT }}$ entre as moléculas da superfície (s) imersa em água (a) foi calculada pelo somatório das componentes apolar e polar da energia livre de interação, $\Delta \mathrm{G}_{\text {sas }}{ }^{\mathrm{LW}} \mathrm{e}$ $\Delta \mathrm{G}_{\mathrm{sas}}{ }^{\mathrm{AB}}$, respectivamente, de acordo com as equações propostas por VAN OSS (1994). Para chegar aos valores finais de energia livre de interação hidrofóbica e energia livre de adesão, é necessária a medida dos ângulos de contato das superfícies de cenoura e das superfícies bacterianas, empregando três líquidos de polaridades diferentes: água, formamida e alfabromonaftaleno, uma vez que estes já possuem valores conhecidos para as tensões interfaciais.

$$
\Delta G_{\text {sas }}^{\text {tot }}=\Delta G_{\text {sas }}^{L W}+\Delta G_{\text {sas }}^{A B}(1)
$$

Já a energia livre de adesão $\left(\Delta \mathrm{G}_{\text {adesão }}\right)$ pode ser representada da seguinte forma:

$$
\begin{gathered}
\Delta G_{\text {ades ão }}=\Delta G_{b l s}^{L W}+\Delta G_{b l s}^{A B}(2) \\
\Delta G_{b l s}^{L W}=\gamma_{b s}^{L W}-\gamma_{b l}^{L W}-\gamma_{s l}^{L W} \text { (3) }
\end{gathered}
$$




$$
\Delta G_{b l s}^{A B}=\gamma_{b s}^{A B}-\gamma_{b l}^{A B}-\gamma_{s l}^{A B}(4)
$$

em que $b$ : bactéria; $l$ : líquido e $s$ : superfície; $\gamma$ : tensão interfacial.

O valor de $\Delta \mathrm{G}_{\text {adesão }}$ permite fazer uma avaliação termodinâmica do processo de adesão entre as bactérias e a superfície dos produtos minimanente processados, sendo esta termodinamicamente favorável quando $\Delta \mathrm{G}_{\text {ades̃o }}<0$ e, ao contrário, desfavorável quando $\Delta \mathrm{G}_{\text {adesão }}>0$.

Detecção de prata no produto minimamente processado por absorção atômica

Após a obtenção dos produtos minimamente processados, foi realizada a quantificação de prata residual por absorção atômica. Foram pesados 10 $\mathrm{g}$ de amostra e conduzidos ao forno a $100^{\circ} \mathrm{C}$ para secagem da amostra. A temperatura foi aumentada à taxa de $50^{\circ} \mathrm{C}$ por minuto até se atingir $450^{\circ} \mathrm{C}$ e essa temperatura foi mantida por $4 \mathrm{~h}$. As cinzas foram dissolvidas em $\mathrm{HCl}$ a $10 \%(\mathrm{v} / \mathrm{v})$ a quente e o volume final ajustado para $50 \mathrm{~mL}$. As concentrações dos elementos foram determinadas em um aparelho Espectrofotômetro de Absorção Atômica (Specttr AA-200 VARIAN). Foram utilizadas lâmpadas monoelemento de cátodo oco para as análises. As concentrações das amostras foram analisadas com base na leitura de quatro diferentes concentrações das soluções padrão do elemento em questão.

Análise estatística dos resultados

Todos os experimentos foram conduzidos em um delineamento inteiramente casualizado, com três repetições. Os dados foram analisados por meio da Análise de Variância (teste F) a 5\% de probabilidade e, uma vez constatado o efeito significativo do tratamento, aplicou-se então o teste Tukey, a 5\% de probabilidade. Todas as análises foram realizadas no software estatístico SAS ${ }^{\circledR}$ (Statistical Analysis System, version 9.1).

\section{RESULTADOS E DISCUSSÃO}

\section{Redução da contaminação microbiana}

A redução significativa da população microbiana no produto ocorre durante a etapa de sanitização, momento em que se adotam tratamentos com substâncias químicas antimicrobianas. No entanto, a eficiência de um agente antimicrobiano depende de fatores ambientais, que podem agir isoladamente ou em combinação, tais como pH, atividade de água, temperatura, atmosfera e carga microbiana inicial (WILEY, 1994).

No presente estudo, observou-se que as nanopartículas de prata foram mais eficientes na descontaminação da cenoura minimamente processada sobre os mesófilos aeróbios, Pseudomonas ssp, e coliformes a $35^{\circ} \mathrm{C}$, quando comparadas aos agentes antimicrobianos estudados: dicloroisocianurato de sódio e hipoclorito de sódio. Quando se comparou os sanitizantes estudados com o controle água, percebeu-se que, em número de reduções decimais, as nanopartículas de prata proporcionaram maior redução, podendo variar de dois a quatro ciclos logarítmicosa diferença para os outros agentes (Tabela 1). A maior eficiência obtida foi para microrganismos mesófilos, em que se teve maior efeito antimicrobiano.

Sabe-se que o cloro, nas suas várias formas, é o sanitizante mais usado em alimentos e é um antimicrobiano de amplo espectro de ação, que age principalmente por oxidação de enzimas essenciais do metabolismo microbiano. Concentrações de 50 a 200ppm de cloro livre são necessárias para inativar células vegetativas de bactérias e fungos (SIMONS \& SANGUANSRI, 1997), mas a concentração deve ser determinada para cada produto. Entretanto, a redução no número de contaminantes da superfície de frutas e hortaliças é limitada (SÃO JOSÉ, 2012). Em países da Europa como Holanda, Suécia, Alemanha e Bélgica, o uso do cloro em produtos minimamente processados é proibido (RICO et al., 2007).

Tabela 1 - Resultados do número de reduções decimais (log UFC $\mathrm{g}^{-1}$ ) após a sanitização da cenoura minimamente processada, comparando os efeitos dos agentes antimicrobianos com o controle (água).

\begin{tabular}{|c|c|c|c|c|}
\hline Antimicrobianos & $\begin{array}{l}\text { Mesófilos Aeróbios* } \\
\quad\left(\log \mathrm{UFC} \mathrm{g}^{-1}\right)\end{array}$ & $\begin{array}{l}\text { Pseudomonas ssp. } \\
\left(\log \mathrm{UFC}^{-1}\right)\end{array}$ & $\begin{array}{l}\text { Bactérias Láticas* } \\
\left(\log \mathrm{UFC} \mathrm{g}^{-1}\right)\end{array}$ & $\begin{array}{l}\text { Coliformes a } 35^{\circ} \mathrm{C}^{*} \\
\quad\left(\log \mathrm{UFC} \mathrm{g} \mathrm{g}^{-1}\right)\end{array}$ \\
\hline Dicloroisocianurato de sódio $150 \mathrm{mg} \mathrm{L}^{-1}$ & $1,62^{\mathrm{a}}$ & $2,33^{\mathrm{a}}$ & $1,17^{\mathrm{a}}$ & $1,84^{\mathrm{a}}$ \\
\hline Hipoclorito de sódio $100 \mathrm{mg} \mathrm{L}^{-1}$ & $1,29^{\mathrm{a}}$ & $2,73^{\mathrm{a}}$ & $1,26^{\mathrm{a}}$ & $2,21^{\mathrm{b}}$ \\
\hline Nanopartículas de prata $6 \mathrm{mg} \mathrm{L}^{-1}$ & $3,73^{b}$ & $4,66^{\mathrm{b}}$ & $2,40^{\mathrm{a}}$ & $3,14^{\mathrm{c}}$ \\
\hline
\end{tabular}

* Média de três repetições. As médias seguidas pela mesma letra, na mesma coluna, não diferem $(\mathrm{P}<0,05)$ estatisticamente entre si pelo Teste Tukey. 
Observando os resultados obtidos, podese verificar que, para todos os grupos microbianos quantificados, o efeito das nanopartículas de prata diferiu do efeito dos outros tratamentos, com exceção para o grupo das bactérias láticas, em que nenhuma diferença foi observada em relação aos outros sanitizantes. Essa diferença pode ser devido à menor concentração inicial das bactérias láticas na superfície da cenoura, $\log 2,40 \mathrm{UFC} \mathrm{g}^{-1}$, quando se compara com os demais grupos microbianos: log 5,29 $\mathrm{UFC} \mathrm{g}^{-1}$ para mesófilos aeróbios, log 5,93 UFC $\mathrm{g}^{-1}$ para Pseudomonas spp. e log 4,40 UFC g ${ }^{-1}$ para coliformes a $35^{\circ} \mathrm{C}$. Ressalta-se que a eficiência na ação antimicrobiana das nanopartículas de prata é atribuída à habilidade em alcançar os sítios de colonização dos microrganismos presentes no alimento; característica esta decorrente de seu tamanho nanométricoque lhes proporciona maior relação superfície/volume, e também por apresentarem capacidade de penetrar nas fissuras existentes na superfície do produto (SHAHVERDI et al. (2007).

JING et al. (2009), em seus estudos, observaram que as nanopartículas de prata apresentaram amplo espectro de inibição contra as bactérias $\boldsymbol{E}$. coli, Bacillus subtilis, $\boldsymbol{S}$. aureus e Pseudomonas aeruginosa, quando a concentração de partículas de prata foi de $2.000 \mu \mathrm{g} \mathrm{mL}^{-1}$ na suspensão. Já MORONES et al. (2005) testaram nanopartículas em pó dentro de uma matriz de carbono, utilizada para prevenir coalescência durante a síntese. Algumas concentrações de nanopartículas de prata $(0,25,50$, 75 e $100 \mu \mathrm{g} \mathrm{mL}^{-1}$ ) foram avaliadas para as seguintes bactérias: $\boldsymbol{E}$. coli, Vibrio cholerae e P. aeruginosa. Os resultados demonstraram que a concentração de nanopartículas de prata que preveniu a multiplicação bacteriana foi diferente para cada microrganismo, sendo que $\boldsymbol{P}$. aeruginosa e $\boldsymbol{V}$. cholerae foram mais resistentes que $\boldsymbol{E}$. coli. Em concentrações acima de $75 \mu \mathrm{g} \mathrm{mL} \mathrm{m}^{-1}$, não houve multiplicação bacteriana significativa para as bactérias testadas.

Energia livre de interação hidrofóbica e energia livre de adesão

O estudo da hidrofobicidade das superfícies interatuantes em um processo de adesão é de extrema importância, pois esse fator contribui para o favorecimento do fenômeno. Sabe-se que, quando as duas superfícies são hidrofóbicas, a remoção do filme de água entre as duas torna-se facilitado, deixando as moléculas de água livres para interagirem entre elas, aumentando-se a entropia do sistema, o que consequentemente leva a uma redução da variação da energia livre de interação hidrofóbica.
Dessa forma, pode-se dizer que, quando a variação da energia livre de interação hidrofóbica, $\Delta G_{\text {sas }}^{T O T}$ $\left(\mathrm{mJ} \mathrm{m} \mathrm{m}^{-2}\right)$, é negativa, a superfície é dita hidrofóbica. Ao contrário, quando a variação da energia livre de interação hidrofóbica, $\Delta G_{s a s}^{T O T}\left(\mathrm{~mJ} \mathrm{~m}^{-2}\right)$, é positiva, a superfície é dita hidrofílica.

Nesse contexto, observando-se os resultados apresentados na tabela 2, pode-se afirmar que todas as superfícies analisadas, tanto as microbianas, quanto as superfícies de cenoura são hidrofílicas, pois apresentaram valores positivos para $\Delta G_{\text {sas }}^{T O T}$.

Quanto ao estudo da termodinâmica de adesão, pode-se afirmar, de acordo com a equação da energia livre de Gibbs $(\mathrm{dG}=\mathrm{dH}-\mathrm{TdS})$, que, no processo de adesão, há grande contribuição da entropia, sendo, portanto, a adesão um fenômeno entropicamente dirigido. Já com relação à entalpia, devido à quebra de ligação das moléculas de água que solvatam a parte hidrofóbica da superfície, ocorre absorção de energia, provocando aumento da entalpia do sistema. No entanto, o aumento proporcionado pela entropia é maior, uma vez que as moléculas de água que estavam interagindo com as moléculas da superfície de adesão e também solvatando a bactéria ficam livres para fazer diferentes interações. Portanto, de acordo com a teoria da termodinâmica, a adesão é favorecida se a variação da energia livre por unidade de área da superfície for negativa, o que significa que a adesão espontânea é acompanhada por uma diminuição da energia livre do sistema, como previsto pela Segunda Lei da Termodinâmica.

Neste estudo, observou-se que, para todas as combinações avaliadas de espécie bacteriana e cenoura sanitizada, a termodinâmica de adesão foi desfavorável, apresentando maiores valores positivos de $\Delta \mathrm{G}_{\text {adesão }}$ para as interações envolvendo as superfícies de cenoura sanitizadas com nanopartículas de prata (Tabela 2). É importante enfatizar que, mesmo que a energia livre de adesão seja desfavorável, o microrganismo pode aderir, uma vez que outros fatores, como os microbiológicos, dentre os quais podem-se citar presença de flagelos, fimbrias e produção de exopolissacarídeos, podem se sobrepor aos fatores termodinâmicos (ARAÚJO et al., 2009).

Detecção de resíduos de prata após a sanitização na cenoura minimamente processada

O resíduo prata detectado para as amostras de cenoura sanitizadas com nanopartículas de prata (6mg L ${ }^{-1}$ ) foi de $0,610 \mathrm{mg} \mathrm{L}^{-1}$. Percebe-se que o teor residual de nanopartículas de prata no produto pronto 
Tabela 2 - Valores da energia livre de interação hidrofóbica $\left(\Delta G_{\text {sas }}^{T O T}\right.$ ) das superfícies bacterianas e da cenoura após a sanitização e energia livre de adesão $\left(\Delta \mathrm{G}_{\text {adesão }}\right)$ entre diferentes espécies bacterianas e superfícies de cenoura após sanitização com água, hipoclorito de sódio, dicloroisocianurato de sódio e nanopartículas de prata.

\begin{tabular}{|c|c|c|c|}
\hline Superfícies & $\begin{array}{l}\text { Energia livre de interação } \\
\text { hidrofóbica } \Delta G_{\text {sas }}^{T O T}\left(\mathrm{~mJ} / \mathrm{m}^{2}\right)\end{array}$ & Espécie Bacteriana/Superfície & $\begin{array}{l}\text { Energia livre de adesão } \\
\qquad \Delta \mathrm{G}_{\text {adesão }}\end{array}$ \\
\hline S. aureus & 56,579 & S.aureus X cenoura- água & 8,176 \\
\hline E. coli & 29,911 & S.aureus X cenoura- hipoclorito de sódio & 11,863 \\
\hline P.aeruginosa & 26,915 & S.aureus X dicloroisocianurato de sódio & 8,752 \\
\hline L. innocua & 21,971 & S.aureus X NP 6 ppm & 12,557 \\
\hline Cenoura - água (Controle) & 29,621 & E. coli X cenoura- água & 5,8673 \\
\hline $\begin{array}{l}\text { Cenoura - Hipoclorito de } \\
\text { sódio } 100 \mathrm{ppm}\end{array}$ & 31,607 & E. coli X cenoura- hipoclorito de sódio & 9,4536 \\
\hline $\begin{array}{l}\text { Cenoura } \\
\text { Dicloroisocianurato de sódio } \\
150 \text { ppm }\end{array}$ & 29,971 & E. coli X dicloroisocianurato de sódio & 6,4280 \\
\hline Cenoura - NP 6 ppm & 31,914 & E. coli X NP 6 ppm & 10,1279 \\
\hline- & & L.innocua X cenoura- água & 0,3599 \\
\hline- & & L.innocua X cenoura- hipoclorito de sódio & 3,4465 \\
\hline- & & L.innocua $\mathrm{X}$ dicloroisocianurato de sódio & 0,8424 \\
\hline- & & L.innocua X NP 6ppm & 4,0278 \\
\hline
\end{tabular}

NP- nanopartículas de prata.

para o consumo é baixo. Não se tem na legislação ou na literatura exigências ou recomendações quanto ao teor residual de prata em alimentos, mesmo porque as nanopartículas de prata não são ainda aprovadas como agentes antimicrobianos para a sanitização de frutas e hortaliças. É sabido que a prata é o metal que apresenta a menor toxicidade para as células animais. Além da prata, muitos outros metais foram estudados, resultando na seguinte escala de toxicidade contra microrganismos: $\mathrm{Ag}>\mathrm{Hg}>\mathrm{Cu}>\mathrm{Cd}>\mathrm{Pb}>\mathrm{Co}>\mathrm{Au}>\mathrm{Zn}>$ $\mathrm{Fe}>\mathrm{Mn}>\mathrm{Mo}>\mathrm{Sn}$ (NETO et al., 2008).

\section{CONCLUSÃO}

A escolha do agente antimicrobiano a ser aplicado na etapa de sanitização de um produto minimamente processado é de extrema importância, visto que a incidência de microrganismos deteriorantes e patogênicos nesses produtos pode ser significativa, apresentando risco à saúde do consumidor, uma vez que são produtos consumidos in natura. As nanopartículas de prata apresentaram resultados promissores para utilização como agentes sanitizantes por terem apresentado melhores resultados, quando comparadas aos compostos clorados. É importante enfatizar que estudos sobre toxicidade devem ser realizados para garantir a segurança dos consumidores e para que as nanopartículas de prata possam ser usadas na sanitização de alimentos.

\section{AGRADECIMENTOS}

Os autores agradecem à Fundação de Amparo a Pesquisa do Estado de Minas Gerais (FAPEMIG), pelo apoio financeiro.

\section{REFERÊNCIAS}

ARAÚJO, E.A. et al. Gibbs free energy of adhesion of Bacillus cereus isolated from dairyplants on different food processing surfaces evaluated by thehydrophobicity. International Journal of Food Science \& Technology, v.44, p.2519-2525, 2009. Disponível em: <http:// onlinelibrary.wiley.com/doi/10.1111/j.1365-2621.2009.02078.x/pdf>. Acesso em: 05 maio 2008. doi: 10.1111/j.1365-2621.2009.02078.x.

BOAS, E.V.B.V. et al. Tendências na área de processamento mínimo de frutas e hortaliças: avanços tecnológicos. In: SIMPÓSIO BRASILEIRO DE PÓS-COLHEITA - FRUTAS, HORTALIÇAS E FLORES, 2007, Viçosa, MG. Palestras e Resumos do II Simpósio Brasileiro de Póscolheita de Frutas, Hortaliças e Flores. Viçosa: UFV, 2007. p. 109-120.

BUSSCHER, H.J. et al. Measurement of the surface free energy of bacterial cell surface and its relevance for adhesion. Applied and Environmental Microbiology, v. 48, p.980-983, 1984. Disponível em: <http://www.ncbi.nlm.nih.gov/pmc/articles/PMC241661/pdf/ aem00156-0080.pdf $>$. Acesso em: 11 jun. 2013.

DALLAS, P. et al. Silver polymeric nanocomposites as advanced antimicrobial agents: Classification, synthetic paths, applications, and perspectives. Advances in Colloid and Interface Science, v.166, n.1-2, p.119-135, 2011. Disponível em: <http://www. sciencedirect.com/science/article/pii/S0001868611001175>. Acesso em: 05 maio 2015. doi: 10.1016/j.cis.2011.05.008.

DOWNES, F.P.; ITO, K. Compendium methods for the microbiological examination of foods. Washington: American Public Health Association (APHA), 2001. 676p. 
GARCIA, A. et al. Ozone and chlorine treatment of minimlly processed lettuce. Journal of Food Science, v.68, n.9, p.27472751, 2003. Disponível em: <http://www.curriecompany.com/ ccc/images/stories/ozon_and_minimaly_processed_lettuce.pdf $>$. Acesso em: 11 jun. 2013.

GUZMÁN, M.G. et al. Synthesis of silver nanoparticles by chemical reduction method and their antibacterial activity. International Journal of Chemical and Biomolecular Engineering, v.2, n.3, p.104-111, 2009. Disponível em: <http://www.waset.org/journals/ ijcbe/v2/v2-3-21.pdf>. Acesso em: 11 jun. 2013.

JING, A.N.et al. Synthesis of stable silver nanoparticles with antimicrobial activities in room-temperatures ionic liquids. Chemical Research Chinese Universities, v.25, p.421-425, 2009 Disponível em: <http:/www.cjcu.jlu.edu.cn/hxyj/EN/article/ downloadArticleFile.do?attachType=PDF\&id=11961>. Acesso em: 05 maio 2015. doi: 10.1088/0957-4484/16/10/059.

MORETTI, C. L. Panorama Internacional do Processamento Mínimo. In: V Enc. Nac. sobre Processamento Mínimo de Frutas e Hortaliças, 2008, Lavras: Universidade Federal de Lavras, 2008. v. 1. p. 28-33

MORONES, J.R. et al. The bactericidal effect of silver nanoparticles. Nanotechnology, v.16, p.2346-2353, 2005. Disponível em: $<$ http:/www.ncbi.nlm.nih.gov/pubmed/20818017>. Acesso em: 05 maio 2015. doi: 10.1088/0957-4484/16/10/059.

NETO, E.A.B. et al. Síntese de nanopartículas de prata para aplicação na sanitização de embalagens. São Carlos: Empresa Brasileira de Pesquisa Agropecuária, 2008. 4p. (Comunicado Técnico, 99).

RICO, D. et al. Extending and measuring the quality of freshcut fruit and vegetable: a review. Trends in Food Science and
Technology, v.18, n.7, p.373-386, 2007. Disponível em: <http:// arrow.dit.ie/cgi/viewcontent.cgi? article $=1027 \&$ context $=$ schfseha rt>. Acesso em: 05 maio 2015 .

SÃO JOSÉ, J.F.B.; VANETTI, M.C.D. Effect of ultrasound and commercial sanitizers on natural microbiota and Salmonella enterica Typhimurium on cherry tomatoes. Food Control, v. 24 n.1-2, p.95-99, 2012. Disponível em: <http://www.sciencedirect. com/science/article/pii/S095671351100363X>. Acesso em: 05 maio 2015. doi:10.1016/j.foodcont.2011.09.008

SHAHVERDI A.R. et al. Synthesis and effect of silver nanoparticles on the antibacterial activity of different antibiotics against Staphylococcus aureus and Escherichia coli. Nanomedicine, v.3, p.168-171, 2007. Disponível em: <http://www.sciencedirect.com/ science/article/pii/S1549963407000469>. Acesso em: 05 maio 2015. doi:10.1016/j.nano.2007.02.001

SIGUA, G. et al. Comparative efficacies of various chemical sanitizers for warewashing operations in restaurants. Food Control, v.22, p.14-15, 2010. Disponível em: <http://www.sciencedirect. com/science/article/pii/S0956713510001702>. Acesso em: 11 jun. 2013. doi: 10.1016/j.foodcont.2010.05.003.

SIMONS, L.K.; SANGUANSRI, P. Advances in the washing of minimally processed vegetables. Food Australia, v.49, n.2, p.75-80, 1997. Disponível em: <http://www.aseanfood.info/ Articles/11005098.pdf>. Acesso em: 11 jun. 2013.

VAN OSS, C.J. Interfacial forces in aqueous media. New York: Marcel Dekker, 1994. 440p.

WILEY, R.C. Introduction to minimally processed refrigerated fruits and vegetables. In: WILEY, R.C. Minimally processed refrigerated fruits \& vegetables. New York: Chapman \& Hall, 1994. Cap.1, p.1-14. 